\section{Palaeontology for the public}

\author{
Tony Thulborn
}

The Dinosaur Heresies: New Theories Unlocking the Mystery of the Dinosaurs and Their Extinction. By Robert T. Bakker. Morrow, New York: 1986. Pp.481. $\$ 19.95 .^{*}$

MORE than 12 years ago Robert Bakker provoked a heated controversy by insisting that dinosaurs were warm-blooded, intelligent and agile creatures bearing litthe resemblance to existing reptiles. Few scientists were entirely convinced by his arguments, though many conceded that there were probably some nuggets of truth among his more extravagant notions. Bakker's claims also roused some outspoken critics, who found his arguments as galling and insubstantial as a swarm of midges, and even today the subject is guaranteed to excite lively discussion which usually ends in stalemate.

Now, in this fiercely partisan book, Bakker seeks to revive the great debate. Yet, surprisingly, he does not return to the fray with any new or more compelling arguments: instead he offers a catalogue of casual opinions and grand generalities, while his underlying arguments recede further into the background or are dismissed as briefly as possible. In essence the book is an inflated compendium of Bakker's ideas about dinosaurs, garnished with exuberant illustrations.

Despite the publisher's hyperbole, this book is not "a full-fledged, highly respectable work of scholarship": it is rhetorical rather than descriptive or analytical, and contains relatively little in the way of hard facts. It is also unashamedly one-sided in its presentation of ideas. Criticisms of Bakker's work (and there have been plenty of them) are simply shrugged aside or ignored entirely, whereas Bakker's own views, however outlandish, are presented as logically inescapable realities. So, for example, the brontosaurs must have given birth to live young because they were "too big to be laid in eggs" (p.357); the Triassic reptile Lagosuchus is "a good candidate for proto-pterodactyl" because it was lightly built and had its neck curved into an S-bend (p.293); and predatory dinosaurs such as Ornitholestes "succeeded in keeping the Mammalia small for over one hundred million years" (p.98). There are scores of such contentious propositions and speculations, all unblushingly presented as sound scientific opinion.

The book is written in an exaggerated

*To be published in Britain by Longman with the subtitle A Revolutionary View of the Dinosaurs. Provisional price is $£ 14.95$ and month of publication April. style, studded with superlatives to end all superlatives. Dinosaurs are not merely impressive or awesome, they are "superhuge" or "super-giant", and they constitute nothing less than a "megadynasty" that suffered "mass murder" at the end of the Cretaceous. Numerous line-drawings depict these "perfectly adapted masters of the terrestrial ecosystem" in suitably energetic postures: the three-ton stegosaur Diracodon teeters precariously on one foot, and the bird-like theropod Deinonychus squabbles amid a flurry of feathers. The splendidly imaginative illustrations are Bakker's own work, and the book is worth purchasing for these alone.

As Bakker admits, many of the theories he presents are developed from ideas in the older literature and in the works of extant authors (who are not always identified by name). But my greatest grumble is with Bakker's grotesque caricature of palaeontology and its practitioners. Those

\section{Storage facilities}

\section{Daniel L. Schacter}

Working Memory. By Alan Baddeley. Clarendon: 1986. Pp.289. £30, \$45.

IN THE late $1960 \mathrm{~s}$, one of the proudest achievements in all of cognitive psychology was the emergence of a detailed theoretical account of an entity known as the short-term store - a kind of mental buffer system that could hold a limited number of items for brief intervals before they were transferred to long-term storage. Theories of the short-term store were often characterized by impressive mathematical precision, and they converged upon a common view that came to be known as the modal model. Some psychologists talked enthusiastically - and in retrospect, perhaps naively - of focusing theoretical attention on problems of longterm memory because the problem of the short-term store appeared to be solved. Then the roof fell in. Within the span of a few short years, experimental data appeared that were inconsistent with the modal model, compelling arguments were advanced that seriously undermined the very notion of a short-term store and the once orderly field of short-term memory was plunged into theoretical disarray.

All was not lost, however. In 1974, Alan Baddeley and Graham Hitch published an article that suggested a new agenda for research on short-term memory. Their agenda consisted of two key items: a theoretical framework that attempted to overcome problems associated with the modal model, and a general approach towards the study of short-term memory processes in a range of cognitive activities, who don't happen to share Bakker's views about dinosaurs appear to be bumbling and unimaginative drones, so devoid of intellectual activity that they are barely distinguishable from the fossils they study. And, between the lines, a gullible reader might gather that sound palaeontological theory may be cobbled together by anyone with a smattering of knowledge and a vivid imagination. Bakker stresses that palaeontology is a hard science, but his style of argument would scarcely convince anyone of that fact.

Palaeontologists will probably react to this book with amusement, incredulity or anguish, depending on the extent of their professional involvement with dinosaurs. Non-specialists are likely to deem it a tour de force, though they should be warned not to swallow too many heresies without an occasional pinch of salt.

Tony Thulborn is a Senior Lecturer in the Department of Zoology, University of Queensland, St Lucia, Brisbane, Australia 4067.

including comprehending, reading and reasoning. In Working Memory, Baddeley reviews and assesses a decade's worth of research that has been pursued in the context of the agenda that he and Hitch set out. Judging by the material in this highly readable and comprehensive monograph, that agenda has proved to be an exceptionally fruitful one.

One of the main differences between the modal model of the 1960 s and Baddeley's working memory model is that the former depicted the short-term store as a unitary entity, whereas the latter fractionates working memory into several components. The critical components are the central executive, a sort of generalpurpose processor which is involved in decision, selection and control functions, and two subordinate or slave subsystems - the articulatory loop, which is crucial for temporary storage of speech-based information, and the visuo-spatial scratchpad, which can hold and represent a limited amount of visual and spatial information. More generally, Baddeley advocates that this system, or something like it, operates as a kind of mental workspace where information can be temporarily held and used in the service of performance on a wide variety of cognitive tasks.

Most of the studies carried out by Baddeley and others within the framework of working memory use a similar experimental strategy. Subjects typically perform a primary task, which may involve reading, comprehension, problem-solving or reasoning. At the same time, they also perform a secondary task, such as rehearsing and then recalling a small set of digits, which is presumed to draw on the capacity of working memory. The major question is whether performing the secondary task disrupts performance of the primary task. 